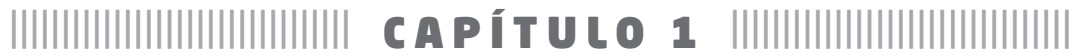

\section{INTERCÂMBIO CULTURAL DOS DISCENTES DE TECNOLOGIA EM SECRETARIADO: UMA EXPERIÊNCIA NA EDUCACÃO PROFISSIONAL DE CARAPICUIBA}

\author{
MAGALI AMORIM MATA ${ }^{1}$
}

IVANETE BELLUCI PIRES DE ALMEIDA²

profissão de Secretariado, em sua atual configuração no
Brasil, deriva do desenvolvimento e transformações eco-
nômico-sociais que resultaram em um agente de conexão dos diferentes públicos do ambiente organizacional. É imperativo deter habilidades de comunicação, não apenas em seu idioma nativo, mas igualmente em idiomas estrangeiros. $\mathrm{O}$ projeto pedagógico do Curso Superior de Tecnologia em Secretariado das Faculdades de Tecnologia do Centro Estadual de Educação Tecnológica Paula Souza estabelece como perfil profissional do egresso, um tecnólogo que, entre outras funções, esteja apto a "redigir textos profissionais especializados, inclusive em idioma estrangeiro", bem como "planejar, dirigir e controlar o processo de comunicação da empresa, inclusive em idioma estrangeiro". Grifo das autoras (Fatec, 2011 p. 1).

1 Mestre em Gestão e Desenvolvimento da Educação Profissional pelo Centro Estadual de Educação Tecnológica Paula Souza. Bacharel como Secretário Executivo Bilingue pela PUCSP. Especialista em Marketing e Propaganda pela ESPM-SP. Coordenador do Curso Superior de Tecnologia em Secretariado da Faculdade de Tecnologia de Carapicuíba no quadriênio 2013-2017. E-mail: magali.mata@fatec.sp.gov.br

2 Doutora em Educação pela Unicamp, do Grupo de Pesquisa Avaliação e Formação de Professores. Professora-orientadora do Programa de Mestrado Profissional em Gestão e Desenvolvimento da Educação Profissional do Centro Estadual de Educação Tecnológica Paula Souza. Diretora da Faculdade de Tecnologia do Tatuapé. E-mail: ivanete.bellucci@gmail.com. 
Na organização curricular desse projeto pedagógico, com vistas a entregar ao mercado de trabalho um tecnólogo capacitado a atuar como agente facilitador do processo de comunicação corporativa, a matriz apresenta uma carga de 440 horas de língua inglesa, 360 horas de língua portuguesa e 320 horas de língua espanhola, perfazendo o total de 1.120 horas em línguas. Contudo, há uma diferença, a menor, de 120 horas entre a carga horária de língua espanhola e de língua inglesa (Fatec, 2011).

O primeiro idioma estrangeiro que se busca aprender no Brasil é o inglês. A influência sociocultural da língua inglesa é muito forte. O alunado é influenciado por este idioma desde sua tenra idade por meio da massiva produção cinematográfica e musical, tanto norte-americana quanto inglesa. Jogos e dispositivos da tecnologia da informação em sua maioria apresentam o inglês como idioma padrão. Entretanto, o Brasil é o único país da América do Sul cujo idioma oficial é a língua portuguesa, quando em todos os outros países do continente sul-americano o espanhol é o idioma oficial. Com a constituição do Mercosul em 1991, iniciou-se uma busca por se aprender o idioma espanhol, até então relegado a um segundo ou até mesmo terceiro plano. Se ao profissional de Secretariado é demandada uma atuação em que para o processo comunicacional é imperativo o domínio de línguas estrangeiras, como dominar a língua 'hermana', na mesma velocidade em que se aprende a língua inglesa? Como se dá o aprendizado desse idioma, que apesar de sua similaridade com a língua portuguesa, por serem ambas de origem greco-latina, apresenta porém acentuada distinção; como se consolida sua assimilação?

$\mathrm{O}$ ambiente de aprendizagem não se restringe somente à sala de aula (Oliveira e Gastal, 2009). É sabido que aprender um outro idioma engloba igualmente aprender acerca da cultura local. Até 
um passado bem recente, pouco se buscava o conhecimento acerca da cultura dos países vizinhos ao Brasil, ainda que localizados no mesmo continente.

Em setembro de 2012, o Centro Estadual de Educação Tecnológica Paula Souza firmou um acordo de cooperação técnica com uma Instituição de Ensino Superior na Argentina, a Universidad Tecnológica Nacional - UTN, com o objetivo de propiciar a troca mútua e o intercâmbio de conhecimentos. Desta feita, a coordenação do Curso Superior de Tecnologia em Secretariado da Faculdade de Tecnologia de Carapicuíba empreendeu o primeiro Intercâmbio Cultural Internacional exclusivamente com alunos do CST em Secretariado, com vistas à otimização do aprendizado do Idioma e vivência cultural.

\section{O INTERCÂMBIO}

A Universidad Tecnológica Nacional - UTN, criada em 1959, conta atualmente com trinta e duas faculdades regionais distribuídas em todo território argentino. Oferece cursos superiores de Tecnologia gratuitos, com foco central na área das engenharias e tem como objetivo a formação profissional para atender às necessidades da indústria argentina (UTN, 2015).

Possui estreita similaridade acadêmica com as faculdades de tecnologia do Centro Paula Souza, criadas em 1969, atualmente com sessenta e seis unidades distribuídas no estado de São Paulo, igualmente oferecendo ensino tecnológico gratuito com vistas à formação profissional para atender ao mercado de trabalho brasileiro. $\mathrm{O}$ convênio assinado entre as duas IES, em 3 de setembro de 2012, objetiva "estender a parceria para projetos de interesse comum em atividades acadêmicas, científicas e tecnológicas" (Centro Paula Souza, 2012). 
Nasceu da experiência de um grupo da Fatec de Guaratinguetá, constituído por 30 alunos dos cursos tecnológicos de Comércio Exterior, Logística, Gestão Empresarial e Gestão Financeira daquela unidade, acompanhados por sete professores de língua espanhola que, durante uma semana do mês de julho 2012, vivenciaram o aprendizado do idioma, além de realizar visitas técnicas ao Centro Metropolitano de Desenho, organismo especializado em produção têxtil, à Câmara de Comércio Argentina e ainda a uma unidade fabril da Volkswagen, em Buenos Aires, na Argentina.

O intercâmbio possui uma dinâmica e proposta muito significativas, não apenas com vistas ao efetivo aprendizado da Língua Espanhola, mas também com relação à formação específica do aluno e sua vivência cultural. O programa é constituído por uma semana de imersão temática e cultural, iniciando-se em um domingo, quando o grupo chega a Buenos Aires, e terminando-se em um sábado, quando o grupo tem um dia livre. A composição da semana de estudos compreende vinte horas, sendo quatro horas por dia com aulas de língua espanhola, tanto gramática quanto aulas específicas com foco no curso de formação do alunado, seguidas de visitas técnicas em instituições argentinas ligadas à área de formação. As despesas decorrentes desse intercâmbio envolvem hospedagem, aulas na universidade, almoços diários na IES, jantar típico em uma churrascaria argentina, seguro-viagem, city tour e o transporte local diário, desde a chegada ao retorno ao aeroporto, bem como o transporte aéreo do Brasil à Argentina, sendo de responsabilidade de cada participante. Por se tratar de um acordo, o valor é atraente e possível de ser assumido, mesmo para os alunos que tenham como fonte de renda exclusivamente seu estágio.

Um escopo muito importante é o de que o intercâmbio não tem como proposta o turismo, mas sim os estudos. Esse tópico é muito 
relevante e, portanto, frisado inúmeras vezes pela UTN, bem como pela coordenação, aos discentes do grupo participante.

\section{O INTERCÂMBIO CULTURAL INTERNACIONAL DOS DISCENTES DE TECNOLOGIA EM SECRETARIADO DA FATEC DE CARAPICUÍBA}

Os discentes do CST em Secretariado da Fatec de Carapicuíba são provenientes dos diversos municípios da região. O grupo do intercâmbio foi constituído por dezoito alunas do quinto ciclo, do semestre de 2013-1, acompanhadas pela Coordenação do Curso e por um professor de Língua Espanhola que igualmente atenderam às aulas, com professores específicos. A maioria das alunas já estagiava, o que lhes propiciou o pagamento das despesas.

O intercâmbio ocorreu de 27 de outubro a 3 de novembro de 2013. Apresentadas ao projeto em abril de 2013, as aluns começaram a pesquisa para obter a melhor tarifa aérea e, em junho de 2013, iniciou-se o pagamento, parcelado pela agência em quatro vezes. Neiva e D'Elia (2013) estabelecem que uma das atribuições do profissional em Secretariado é o planejamento e a organização de viagens nacionais ou internacionais.

O passo seguinte para os discentes foi efetuar uma poupança com vistas às despesas relativas à semana de estudos, cujo pagamento se daria diretamente à UTN, em outubro, quando da chegada a Buenos Aires. Como mencionado, pelo fato de serem estagiárias, a maior parte do grupo pôde assumir suas próprias despesas, indubitavelmente com certa restrição. Algumas obtiveram ajuda financeira de familiares ou amigos e uma aluna obteve ajuda onde empreendia seu estágio. 


\section{A FORMATAÇÃO DA SEMANA DE ESTUDOS}

A primeira Fatec a participar da semana de estudos foi a de Guaratinguetá, em sua experiência inovadora, conforme relatado acima, o que levou à assinatura do convênio. Os intercâmbios passaram efetivamente a acontecer a partir de 2013, com as Fatec de Americana, Guaratinguetá, Jundiaí, Barueri, São Sebastião e Itaquaquecetuba. Nesta última, o grupo era constituído pelos alunos do Curso Superior de Tecnologia em Gestão Comercial e incluiu a participação de cinco alunos do CST em Secretariado, que atendeu à proposta específica daquele curso. A Semana de Intercâmbio Cultural Internacional dos discentes de Tecnologia em Secretariado da Fatec de Carapicuíba se constituiu, porém, no primeiro evento do gênero, em que um grupo, exclusivamente de alunos de Secretariado, atendeu coletivamente a um intercâmbio internacional. A iniciativa empreendida pela Fatec de Carapicuíba, especificamente com os alunos do CST em Secretariado, não tem precedentes no Brasil.

O conteúdo foi construído especificamente para atender ao alunado deste curso. Seu planejamento e organização foram profundamente discutidos entre a diretora do Departamento de Idioma e Espanhol como Língua Estrangeira, vinculado à Secretaria de Cultura e Extensão Universitária da UTN, e a Coordenação do CST em Secretariado da Fatec de Carapicuíba. As reuniões foram realizadas por Skype, com resultados que culminaram num cronograma específico e exclusivo ao discente de secretariado, objeto do intercâmbio.

O formato final da semana se configurou com aulas diárias de língua espanhola, das $9 \mathrm{~h}$ às $10 \mathrm{~h} 30 \mathrm{~min}$. Das $11 \mathrm{~h}$ às $13 \mathrm{~h}$, foram ministradas aulas (em espanhol) com temas específicos à Gestão Secretarial, numa perspectiva internacional para conhecimento da cultura local. Para o primeiro dia de aula, na segunda-feira, o tema 
foi Introducción a la Economía de Argentina. Para o segundo dia, na terça feira, o tema foi Protocolo y Ceremonial, com foco na cultura argentina. Para o terceiro dia, na quarta-feira, o tema abordado foi Mercado laboral \& Gestión de Personas: Políticas y Prácticas en Argentina. No quarto dia, na quinta-feira o tema foi Ambiente de negocios en Argentina.

Para atender às aulas específicas, as alunas foram agrupadas conforme o resultado do teste de nivelamento empreendido no Brasil, pelo docente de língua espanhola, aplicando-se o exame encaminhado pela UTN. Na sexta-feira, último dia efetivo de aulas, todas as classes foram reunidas, independentemente de seu nivelamento, e juntas atenderam ao tema Diferencias culturales Brasil $x$ Argentina, una análisis contrastivo cultural, ocasião em que puderam trocar informações múltiplas e dirimir dúvidas com os professores quanto às questões pertinentes a diferenças culturais entre a realidade brasileira e a realidade visitada (Hall, 2014).

O grupo realizou as refeições do almoço no restaurante do campus, experimentando a autêntica e original culinária cotidiana argentina. Dado o cronograma construído, os horários necessitam ser cumpridos e os atrasos evitados. O grupo cumpriu todos os horários desde a saída do hotel pela manhã ao embarque para as visitas técnicas.

Vale ressaltar que a localização da hospedagem do grupo era bastante privilegiada: a Calle Florida. Muito embora se tratasse de um hostel, cujos serviços são mais simples quando comparados aos de um hotel, o mesmo se localiza a uma quadra da Plaza de Mayo, onde se encontra a Casa Rosada, sede do Poder Executivo argentino. Localiza-se igualmente a cinco minutos de caminhada de Puerto Madero, facilitando o acesso aos restaurantes do local. Ao final da Rua Florida, encontra-se a Plaza San Martin com acesso a outras 
áreas da cidade. Isso enriqueceu ainda mais a experiência vivida pelo grupo em termos de aprendizado da realidade cultural local (Xavier e Fernandes, 2008).

\section{AS VISITAS TÉCNICAS E O CITY TOUR}

$\mathrm{Na}$ tarde da segunda-feira, primeiro dia de atividades, após as aulas da manhã, foi empreendida visita ao campus da UTN em Avellaneda. O grupo foi recebido pelo engenheiro Sebastián Blasco, secretário de Cultura e Extensão Universitária e pelo decano, engenheiro Jorge Del Gener.

Após a recepção, foram visitadas todas as instalações do campus, como laboratórios, quadra poliesportiva e refeitório dos alunos. O que mais chamou a atenção do grupo foi a ambientação, muito próxima à realidade brasileira.

Após a visita ao campus da UTN em Avellaneda, o grupo foi conduzido a um city tour pelos mais famosos e conhecidos pontos turísticos de Buenos Aires, entre eles, os bairros Caminito e Palermo, o estádio La Bombonera, Puerto Madero, finalizando com a Casa Rosada, que fica em frente à Plaza de Mayo. O city tour consistia em paradas efetivas para visitação e compra de souvenirs e iguarias típicas da Argentina como o dulce de leche e os alfajores.

$\mathrm{Na}$ terça-feira, a visita técnica foi realizada à Asociación Iberoamericana de Mujeres Empresarias, AIME, estabelecida nas dependências da Câmara de Comércio Argentina. O Grupo foi recebido pela senhora Julita Maristany, presidente da Associação. Nessa visita a presidente discorreu acerca da importância do papel da mulher na economia argentina e apresentou os resultados empreendidos pela AIME. Abriu-se um espaço para perguntas e para surpresa dos docentes, o grupo mostrou-se seguro e participou ativamente com 
perguntas de muita maturidade acadêmica evidenciando que o ambiente fino e requintado das dependências da Câmara não tolheu sua participação.

$\mathrm{Na}$ quarta-feira, o grupo participou de uma aula de tango organizada pela diretoria da UTN. Os instrutores ensinaram seis passos básicos da dança que é um ícone da cultura argentina. O grupo interagiu sobremaneira e mesmo após o retorno ao Brasil recordava os passos aprendidos.

$\mathrm{Na}$ quinta-feira, o grupo efetuou visita técnica à Asociación de Organización de Eventos, sendo recepcionados pela dirigente Alicia Schiaretti. A visita técnica propiciou o entendimento quanto à posição da Argentina no cenário internacional, como se processa a captação de eventos internacionais a serem sediados em Buenos Aires e o reflexo para a economia local.

$\mathrm{Na}$ sexta-feira, realizou-se a terceira e última visita técnica do intercâmbio, com a ida à Confederación Argentina de la Mediana Empresa: Mujeres Empresarias, CAME. A presidente da entidade, Sandra Nicolás, recepcionou o grupo. Deu seu depoimento pessoal quanto à sua chegada à entidade e os desafios que lhe foram conferidos à frente da instituição. Seu depoimento foi altamente agregador aos discentes, uma vez que versava sobre a superação de obstáculos que se lhe impuseram ante o falecimento do esposo que geria uma fábrica de louçaria no interior da província e todos os desafios que teve que enfrentar e superar. $\mathrm{O}$ apoio por parte da Instituição foi fundamental para a continuidade do negócio. Dado o interesse do grupo e pelo fato de que uma das discentes tinha em vista a abertura de um negócio próprio, a presidente da CAME assumiu o compromisso de estender um treinamento internacional, sendo a aluna do grupo a primeira a ser convidada a participar com a oferta de uma cortesia, com todas as despesas pagas pela instituição. 
Após atender a todas as atividades acima elencadas, desde as aulas de gramática, as aulas dos temas específicos em espanhol, bem como as visitas técnicas, foi outorgado um certificado pela UTN, tanto aos alunos quanto aos professores.

Além das atividades acadêmico-profissionais descritas, o grupo teve a oportunidade de assistir a um show de tango, atividade que não fazia parte da programação oficial, mas que foi assumida pelo grupo. A reação dos discentes, frente a uma das mais significativas facetas culturais da Argentina, que é o tango, foi indescritível: muitas reconheciam, ao ouvir os grupos folclóricos e assistirem à apresentação de dança, o quão importante é presenciar a realidade cultural do país como parte do aprendizado da língua estrangeira.

Após a estadia de oito dias e sete noites num país diferente do seu, quando muitas sequer haviam deixado o estado em que vivem, nunca sequer haviam empreendido uma viagem para fora de sua cidade, configurou-se de um acontecimento ímpar. Pode-se verificar através dos depoimentos de algumas das participantes enviados por e-mail à Coordenação após o intercâmbio:

Depoimento da Aluna Ingrid Cristina Pereira:

[...] a experiência de viajar para Buenos Aires foi incrível, pois eu, com apenas 19 anos, nunca havia saído do estado de São Paulo e não imaginava que a minha primeira viagem fosse para fora do país, essa viagem me foi proporcionada graças ao intercâmbio realizado entre a Fatec Carapicuíba e a UTN - Universidad Tecnológica Nacional, o qual me possibilitou a vivência com a cultura e a língua espanhola de um modo único e abrangente. $\mathrm{O}$ roteiro da viajem foi criado voltado a promover o máximo aproveitamento dos alunos de Secretariado, pois suas aulas, palestras e passeios foram voltados a este público, para que com isso podemos nos tornar 
profissionais mais completos. O intercâmbio é muito rico em conhecimento e todos que tiverem a intenção de ter uma vivência no exterior deveriam optar por este programa [sic].

\section{Depoimento da aluna Andreia Ferreira Pompílio:}

[...] fomos recebidos por uma equipe séria, formada pela diretora da UTN (Universidade Tecnológica Nacional) e um guia divertidíssimo, o Sr. Juan, atencioso, que por onde passávamos sempre nos contava uma história em relação àquele lugar. Nas visitas técnicas não foi diferente; tivemos uma recepção em que era nítida a preocupação com as alunas; éramos tratadas com muito respeito e atenção, atitudes que nos deixaram bastante surpresas. Sim, fomos tratadas como princesas.

As professoras da universidade tiveram um trabalho bastante lúdico, as palestras focadas na profissão do secretariado, e em poucos dias foi possível praticar a língua espanhola, além de conhecer muito sobre um país semelhante ao nosso.

\section{Depoimento da aluna Marisa Santini:}

[...] oportunidade única que foi proporcionada. O intercâmbio fez com que várias portas se abrissem para o mundo coorporativo, no qual, ao dizer em uma oportunidade de emprego que fiz um intercâmbio para a Argentina, os olhos brilharem por falar dessa oportunidade [...] tive a possibilidade de conhecer e respeitar pessoas, a cultura e os costumes do povo argentino, saber que eles respeitam e adoram o nosso país. [...] Em um desses lugares, tive a possibilidade de ficar muito feliz por conhecer uma organização que apoia mulheres empresarias, no qual fizemos muitas perguntas e 
em especial tive a oportunidade de expor a minha pergunta e ao final do encontro tive a felicidade de saber que eles estão planejando um projeto para mulheres de outros países e que esse projeto saindo do papel seria a primeira mulher a ser convidada para realizar o curso para mulheres empresarias na Argentina.

\section{CONSIDERAÇÕES FINAIS}

O tecnólogo em secretariado, ao ser demandado a atuar como agente facilitador no ambiente organizacional, deve deter habilidades linguísticas em idiomas estrangeiros, além de seu idioma nativo, e ser capaz de se comunicar tanto na língua inglesa quanto na língua espanhola, ambas presentes na matriz curricular do curso em referência. O intercâmbio cultural, empreendido na Argentina, proporcionou aos alunos participantes não apenas o aprendizado da língua espanhola, mas também a condição de interação vivencial com a cultura argentina. $\mathrm{O}$ desenvolvimento dos alunos foi notório a cada dia da semana de estudos. No primeiro dia a conversação entre todas se deu ainda na língua portuguesa. Passadas somente vinte e quatro horas, a conversação já se fazia no idioma local, independentemente dos erros cometidos. A cada dia a desenvoltura, a confiança e o aprendizado na língua espanhola ficavam evidenciados. A língua portuguesa passou a ficar relegada a um segundo plano e vivenciaram a prática do idioma local como se fosse sua língua mãe. A melhora nos estudos de espanhol foi visível quando do retorno do intercâmbio. Além da melhora em termos comunicacionais nesse idioma estrangeiro, o intercâmbio, igualmente, fez com que cada participante pudesse se perceber capaz de interagir com cidadãos de uma cultura distinta, adaptando-se rapidamente ao novo cenário 
e vivenciando a experiência com extrema naturalidade. Todas as participantes explicitaram o desejo de repetir a experiência assim que um novo grupo fosse constituído. À IES ficou o sentimento de ter propiciado uma empreitada de alto valor agregado ao alunado.

\section{REFERÊNCIAS}

CENTRO PAULA SOUZA. Paula Souza assina acordo com universidade argentina para intercâmbio de alunos e professores de Fatecs. Disponível em: <http://www.centropaulasouza.sp.gov. br/noticias/2012/setembro/03_paula-souza-assina-acordo-comuniversidade-argentina-para-intercambio-de-alunos-e-professores-defatecs.asp>. Acesso em: 25 jul. 2017.

FATEC - Faculdade de Tecnologia de Carapicuíba. (2011). Projeto Pedagógico do Curso de Tecnologia em Secretariado. Disponível em: $<$ http://www.fateccarapicuiba.edu.br/cursos/grades/SEC.pdf $>$. Acesso em: 15 jun. 2017.

HALL, S. A Identidade Cultural na pós-modernidade. Rio de Janeiro: Lamparina, 2014.

MATA, M. A. Postura profissional para o sucesso no exercício da gestão secretarial. In. PORTELA, K. C. A.; SCHUMACHER, A. J. (Org.).

Gestão Secretarial, o desafio da visão holística. Cuiabá: Adeptus. 2009.

NEIVA, E. G.; D’ELIA, M. E. S. As Novas Competências do Profissional de Secretariado. 3. ed. São Paulo: IOB-Thompson, 2013.

OLIVEIRA, R. I. R.; GASTAL, M. L. de A. Educação formal fora da sala de aula: olhares sobre o ensino de ciências utilizando espaços nãoformais. VII ENPEC 2009. Disponível em: <http://posgrad.fae.ufmg.br/ posgrad/viienpec/pdfs/1674.pdf>. Acesso em: 28 jul. 2015. 
UNIVERSIDAD TECNOLOGICA NACIONAL. Sintésis Histórica. <http://www.utn.edu.ar/institucional/historia.utn>. Acesso em: 15 ago. 2015.

XAVIER, O. S. \& FERNANDES, R. C. A. A Aula em Espaços NãoConvencionais. In: VEIGA, I. P. A. Aula: gênese, dimensões, princípios e práticas. Campinas: Papirus Editora. 2008. 